\title{
Polymer-clay nanocomposites via chemical grafting of polyacrylonitrile onto cloisite 20A
}

\author{
YAGOUB MANSOORI*, KHADIJEH ROOJAEI, MOHAMMAD REZA ZAMANLOO and \\ GHOLAMHASSAN IMANZADEH \\ Department of Applied Chemistry, Faculty of Science, University of Mohaghegh Ardabili, Ardabil 56199-11367, Iran
}

MS received 13 December 2011; revised 12 March 2012

\begin{abstract}
The synthesis and characterization of polyacrylonitrile (PAN) nanocomposites through grafting the polymer onto organophilic montmorillonite have been reported. Cloisite $20 \mathrm{~A}$ reacted with vinyltrichlorosilane to replace the edge hydroxyl groups of the clay with a vinyl moiety. Because the reaction liberates $\mathrm{HCl}$, it was performed in the presence of sodium hydrogen carbonate to prevent the exchange of quaternary alkylammonium cations with $\mathrm{H}^{+}$ions. Only the silanol groups on the edge of the clay reacted with vinyltrichlorosilane. The radical polymerization of the product with acrylonitrile (AN) as a vinyl monomer leads to chemical grafting of polyacrylonitrile onto montmorillonite surface. The homopolymer formed during polymerization was separated from the grafted organoclay by Soxhlet extraction. Chemical grafting of the polymer onto Cloisite $20 \mathrm{~A}$ was confirmed by infrared spectroscopy. The prepared nanocomposite materials and grafted nanoparticles were studied by XRD and TEM. Exfoliated nanocomposites were obtained for $0.5-7 \mathrm{wt} \%$ clay content. The nanocomposites were studied by thermogravimetric analysis (TGA) and dynamic mechanical analysis (DMTA).
\end{abstract}

Keywords. Grafting; polyacrylonitrile; nanocomposites; Cloisite 20A; organophilic clay.

\section{Introduction}

During past decades polymer/layered silicate nanocomposites have attracted great interest, both in industry and in academia, because they often exhibit remarkable improved material properties (Ray and Okamoto 2003). The homogeneous dispersion of organically modified clays in polymer matrices could lead to enhanced thermal stability (Phang et al 2005; Zhao and Wang 2006; Jin and Chang 2008; Rubal et al 2008), mechanical properties (Gintert et al 2007; Jia et al 2008; Stefanescu et al 2008; Njuguna et al 2008; Mansoori et al 2010a,b), gas barrier (Yudin et al 2007; Huang et al 2008), dielectric properties (Gu et al 2001) and solvent resistance (Huang et al 2001) compared to the virgin polymers or conventional micro- and macro-composites. Montmorillonite is the most commonly used layered silicate due to its high cation-exchange capacity, excellent swelling ability, high aspect ratio and ease of modification, which are important for the preparation of clay/polymer nanocomposites (Zhao et al 2009).

PAN is an important thermoplastic from industrial point of view because of its favourable properties. Furthermore, AN can be easily copolymerized with other vinyl monomer and thus the resulting copolymers may be used as plastic resins, fibres or rubbers. It is the most common precursor to create carbon nanofibres (Wang et al 2005; Kim et al 2008; Zhang

\footnotetext{
*Author for correspondence (ya_mansoori@yahoo.com)
}

et al 2009; Nataraj et al 2009; Karimi et al 2011). Heating of PAN over $700^{\circ} \mathrm{C}$ in a non-oxidative atmosphere leads to production of a polyaromatic structure similar to a graphitic sheet (Beretta 2009).

Several research groups have focused their efforts on studying PAN-based nanocomposites using $\mathrm{PbS}$ (Qiao et al 1999), carbon nanotube (Wang et al 2008), CdS (Feng et al 2009) and iron (Zhang et al 2010) as nanofiller. The investigations on polymer layered silicate nanocomposites with homopolymer of PAN have recently been noted. Chung and co-workers reported the synthesis of exfoliated PAN/sodium montmorillonite (Na-MMT) nanocomposites via emulsion polymerization. The nanocomposites showed exfoliated morphology up to $20 \mathrm{wt} \%$ of Na-MMT. Storage moduli of PAN/Na-MMT nanocomposites were enhanced compared with pristine PAN (Choi et al 2002). They have also reported the preparation of exfoliated PAN/Na-MMT nanocomposites using initiators adsorbed on silicate. The initiator adsorbed on silicate commenced the polymerization of $\mathrm{AN}$, delaminating silicate layers in PAN/Na-MMT nanocomposites (Choi and Chung 2004). Yu et al (2007) reported the co-incorporation of two different forms of nanomaterials into polymer matrix. They synthesized $\mathrm{PAN} / \mathrm{Na}-\mathrm{MMT} / \mathrm{SiO}_{2}$ nanocomposites via in situ emulsion polymerization. It was found that the PAN/Na-MMT/SiO 2 nanocomposites exhibit considerably enhanced moduli compared with the PAN/ $\mathrm{Na}-\mathrm{MMT}$ and $\mathrm{PAN} / \mathrm{SiO}_{2}$ nanocomposites due to the synergistic reinforcing effect (Yu et al 2007). Yang et al prepared organically modified Na-MMT with 12-aminododecanoic 
acid as filler to prepare a series of composite polymer electrolytes based on PAN and $\mathrm{LiClO}_{4}$. It was found that the organoclay particles were well dispersed in the composite polymer electrolytes and the corresponding cell exhibited excellent electrochemical stability and cyclability (Yang et al 2009). Recently, Sun et al (2010) reported the preparation and characterization of novel nanocomposites based on PAN/kaolinite by a simple in situ emulsion polymerization. The crude kaolinite was firstly modified by dimethylsulfoxide-methanol and potassium acetate-aqueous systems. AN was then intercalated into kaolinite by displacing potassium acetate from KAc-kaolinite. It was observed that the presence of clay results in an increase in molecular weights compared to pure PAN polymer due to the highly crosslinked structure (Sun et al 2010).

One of the major problems in preparing nanocomposite materials based on organoclay is the hydrophilicity of the clay that makes the clay less compatible with the organic polymers. Several efforts have been made to modify the inorganic clay with organic polymers for a better compatibility. These methods include incorporation of AIBN-type initiator into the intergalleries of the clay by ion exchange reaction (Fan et al 2003a,b), synthesis of ionically bound methacryl type monomer (Mittal 2007), grafting of polymers from clay nanoparticles via high-dose gamma-ray irradiation (Wang et al 2007), surface-initiated redox polymerization (Chen et al 2010a), and grafting of polymers onto inorganic substrates via surface-initiated atom transfer radical polymerization (Chen et al 2010b).

Nevertheless, clay remains hydrophilic after these modifications. This hydrophilic nature can be attributed to the polar silanol groups located at the edges of layered silicates. To make the organoclay more compatible with polymers, the edge silanol groups can be replaced with polymer chains that make the organoclay more compatible with the polymer to be used later (especially if both polymers are the same). Using of mono- and tri-functional organo-alkoxysilane derivatives carrying a terminal reactive methacryloyl group, as reagents for sylilation of synthetic Laponite clay platelets, have been reported by Herrera et al (2004). Polymer grafting was performed by emulsion polymerization of the silylated clay in the presence of styrene and butyl acrylate at $70^{\circ} \mathrm{C}$ for up to $24 \mathrm{~h}$ (Herrera et al 2004). A major drawback of the method is the susceptibility of the $\mathrm{Si}-\mathrm{O}-\mathrm{C}$ linkage, which connects the polymer chain onto inorganic substrate, to hydrolysis in aqueous solutions (Gorgani et al 1985). In order to overcome this problem, Agudelo et al (2011) reported the synthesis of random copolymers based on poly(styrene-co-triethoxyvinylsilane) and their application as macrosilanes for grafting silica particles with PS chains. We also recently reported the grafting of polyacrylamide, poly(methyl methacrylate) (Mansoori et al 2010a,b), and polyvinyl acetate (Mansoori et al 2011) onto Cloisite 20A. In these methods, the polymer chain was grafted onto the inorganic substrates via a strong $\mathrm{Si}-\mathrm{C}$ linkage that was quite stable in acidic and weak alkaline aqueous media (Waddell et al 1981).
In the present study, we wish to report the grafting of PAN onto Cloisite 20A nanoparticles. Organophilic clay was vinyl-modified by silylation reaction with vinyltrichlorosilane and then free radically co-polymerized with $\mathrm{AN}$ in the presence of benzoylperoxide (BPO) as an initiator. The grafted polymer acts as a compatibilizer between the polymer and the clay phases because both the polymers have the same polarity. Chemical grafting of the polymer onto the surface of Cloisite 20A was clearly confirmed by FTIR spectroscopy after Soxhlet extraction and separation of homopolymer. The prepared nanocomposites and grafted nanoparticles were studied by XRD and TEM. The properties of the nanocomposites were investigated by conventional TGA and DMTA techniques.

\section{Experimental}

\subsection{Materials}

The commercial nanoclay Cloisite 20A was purchased from Southern Clay Products (Gonzales, TX) and dried under vacuum at $60^{\circ} \mathrm{C}$ for $24 \mathrm{~h}$ before silylation. Vinyltrichlorosilane and AN were obtained from Fluka Co. and Merck Co., respectively. BPO was obtained from Merck Co. and recrystallized from ether prior to use. All other chemicals were of reagent grade and were used without further purification.

\subsection{Measurements}

FTIR (KBr) spectra were recorded on a Perkin Elmer RXI spectrophotometer $\left(2 \mathrm{w} / \mathrm{w} \%\right.$ in $\mathrm{KBr}$, resolution, $4 \mathrm{~cm}^{-1}$, number of scans, 6). TGA and DMTA curves of the powdered samples were obtained on Linseis STA PT 1000 and Triton Tritec 2000 DMN instruments, respectively. Wide angle X-ray diffraction (XRD) measurements were performed at room temperature on a Italstructures MPD3000 $\mathrm{X}$-ray diffractometer by using $\mathrm{Ni}$-filtered $\mathrm{Co}-\mathrm{K}_{\alpha}$ radiation. The scanning rate was $1^{\circ} / \mathrm{min}$ over a $2 \theta$ range of 2 $10^{\circ}$. TEM images of nanocomposite samples were obtained by using a transmission electron microscope (EM $208 \mathrm{~S}$, Philips, The Netherlands) with an acceleration voltage of $100 \mathrm{kV}$. Prior to TEM experiment, the nanocomposite sample was completely dried under vacuum and then embedded in an epoxy matrix. Subsequently, it was cut into a $70-100 \mathrm{~nm}$ thick section with a diamond knife and placed onto a 400 mesh copper grid.

\subsection{Preparation of vinyl-modified clay}

The preparation of vinyl-modified clay was performed according to the method described earlier (Mansoori et al 2010a,b). $10 \mathrm{~g}$ portion of Cloisite 20A and $\mathrm{NaHCO}_{3}(42 \mathrm{~g}$, $0.5 \mathrm{~mol}$ ) were placed in a $500 \mathrm{ml}$ three-neck round bottom flask charged with $300 \mathrm{ml}$ of anhydrous acetone. The system was vigorously stirred under nitrogen for $15 \mathrm{~min}$. Then a $50 \mathrm{ml}$ portion of vinyltricholorosilane was added drop wise 
to the suspension over $3 \mathrm{~h}$. The mixture was gently refluxed for $8 \mathrm{~h}$ and the product was filtered, successively washed with acetone, acetone $/ \mathrm{H}_{2} \mathrm{O}(50 / 50)$, filtered, dried under vacuum at $40^{\circ} \mathrm{C}$, and stored for the subsequent experiments: FTIR (KBr): 3635 ( $m, \mathrm{OH}), 3064$ ( $w$, vinylic $\mathrm{CH}), 2927$ ( $m$, surfactant), 2853 ( $m$, surfactant), $1041 \mathrm{~cm}^{-1}(s, \mathrm{Si}-\mathrm{O})$.

\subsection{Polymer grafting}

In a three-necked round bottomed flask equipped with a magnetic stirrer and a reflux condenser, silylated Cloisite 20A (5 g), AN (1.482 g, $28 \mathrm{mmol})$ and BPO (0.130 g, 0.54 mmol) were placed in $15 \mathrm{ml}$ of DMF. The flask was purged by dry, oxygen-free argon for $20 \mathrm{~min}$. The system was heated and magnetically stirred at $90-95^{\circ} \mathrm{C}$ for $8 \mathrm{~h}$. Then the reaction mixture was transferred into a Soxhlet apparatus and extracted with $\mathrm{CH}_{2} \mathrm{Cl}_{2}$ for $72 \mathrm{~h}$. The grafted powder was then dried at $40^{\circ} \mathrm{C}$ for $24 \mathrm{~h}$ in a vacuum oven. FTIR (KBr): 3632 ( $m, \mathrm{OH}), 2927$ ( $m$, surfactant), 2855 ( $m$, surfactant), 2246 $(w, \mathrm{C} \equiv \mathrm{N}), 1040 \mathrm{~cm}^{-1}(s, \mathrm{Si}-\mathrm{O})$.

\subsection{Blank experiment}

The blank experiment was performed under same conditions using unmodified Cloisite 20A.

\subsection{Typical procedure for preparing PAN clay nanocomposite, $1 \mathrm{wt} \%$}

In a three-necked round bottomed flask equipped with a magnetic stirrer and a reflux condenser, silylated Cloisite 20A
(0.040 g) was dispersed in $15 \mathrm{ml}$ of DMF. The suspension was stirred at room temperature for $24 \mathrm{~h}$ under argon. AN (4 g, $75.5 \mathrm{mmol})$ and BPO $(0.360 \mathrm{~g}, 1.49 \mathrm{mmol})$ were added and the mixture was stirred at room temperature for an additional $24 \mathrm{~h}$ under argon. The reaction mixture was heated at $90-95^{\circ} \mathrm{C}$ for $8 \mathrm{~h}$. The viscose suspension was trickled slowly into $100 \mathrm{ml}$ of $\mathrm{MeOH}$ while vigorous stirring, filtered, thoroughly washed with $\mathrm{MeOH}$ and then dried at $60^{\circ} \mathrm{C}$ for $24 \mathrm{~h}$ in a vacuum oven.

\section{Results and discussion}

Organophilic clay, Cloisite 20A, was silylated with vinyltrichlorosilane. Because the reaction liberates $\mathrm{HCl}$, it is very important that the quaternary alkylammonium cations are not exchanged with $\mathrm{H}^{+}$ions. If the protons are not removed, the silylation reaction can occur on both external and internal surfaces, decreasing the basal spacing. The internal surface silylation is eliminated by capturing the protons with a base such as sodium hydrogen carbonate so that the basal spacing almost was not changed (Zhang et al 2006). In the IR spectrum of the silylated Cloisite 20A (figure 1b), absorption bands appeared at $3064 \mathrm{~cm}^{-1}$ and $3029 \mathrm{~cm}^{-1}$ that can be attributed to the stretching of the vinylic $\mathrm{C}-\mathrm{H}$ bonds. In the next step, vinyl-modified Cloisite 20A was copolymerized with AN by free-radical polymerization reaction in the presence of BPO as an initiator (scheme 1).

To confirm the grafting reaction by conventional analytical methods, the homopolymer must be separated from the

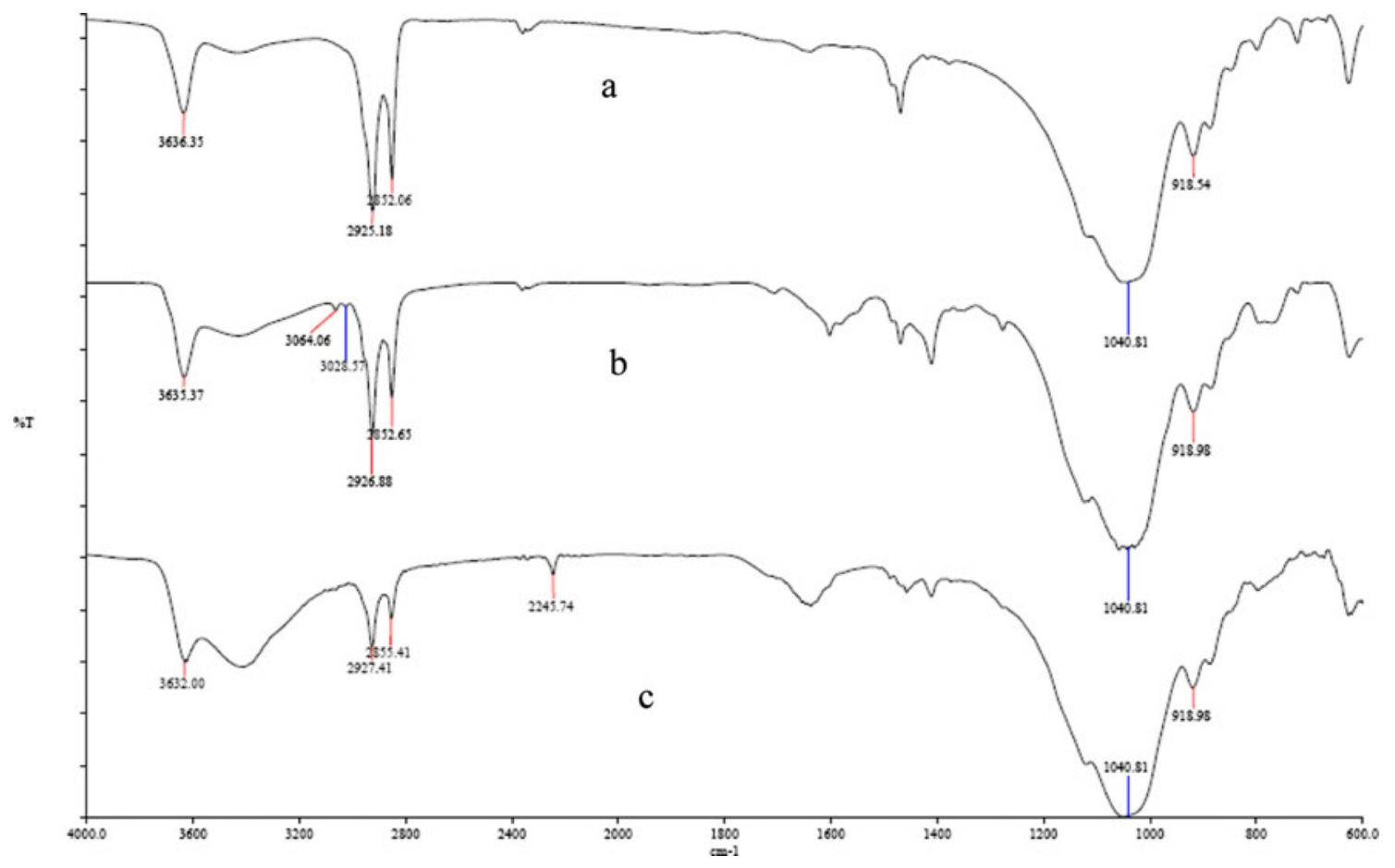

Figure 1. FTIR spectrum (KBr) of (a) Cloisite 20A, (b) silylated Cloisite 20A and (c) polyacrylonitrile-grafted Cloisite 20A. 


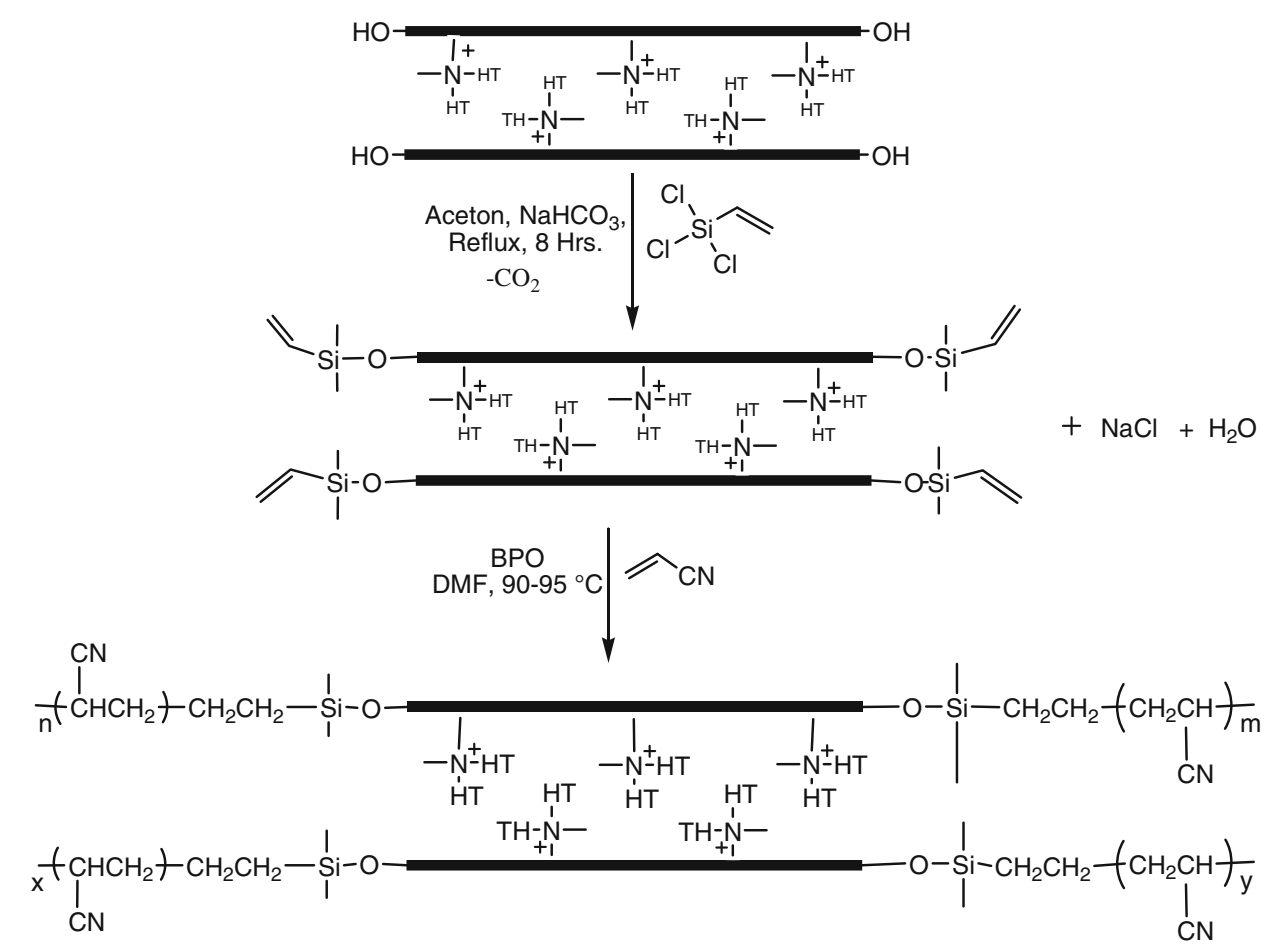

Scheme 1. Hydrogenated Tallow (HT) is derived from natural product with average 17 number of carbon.

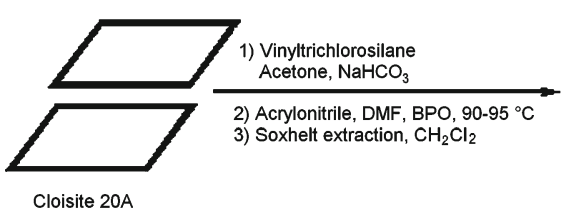

Poly(acrylonitrile)-grafted Cloisite 20A

Figure 2. Schematic representation for a PAN-grafted Cloisite 20A.

grafted organoclay particles. For this reason, after completion of polymerization, the product was extracted by using Soxhlet apparatus with $\mathrm{CH}_{2} \mathrm{Cl}_{2}$ to remove the homopolymer. The complete removal of the homopolymer was confirmed by doing a blank polymerization experiment with the unmodified Cloisite 20A. After $72 \mathrm{~h}$ of Soxhlet extraction of the blank experiment product with dichloromethane, FTIR spectrum observed was the same as that for Cloisite 20A, and the absorption bands related to PAN were not observed. In the FTIR spectrum of the separated Cloisite 20A grafted with PAN, the absorption band observed at $2246 \mathrm{~cm}^{-1}$ is related to nitrile stretching. The strong, broad band in the region of $1000-1160 \mathrm{~cm}^{-1}$ is likely due to siloxane $(\mathrm{Si}-\mathrm{O}-\mathrm{Si})$ bond (figures 1a-c).

The radical polymerization of acrylonitrile with different amounts of vinyl-modified organoclay in the presence of BPO in DMF leads to the formation of PAN-clay nanocomposite materials (PCNs) in which some PAN chains are

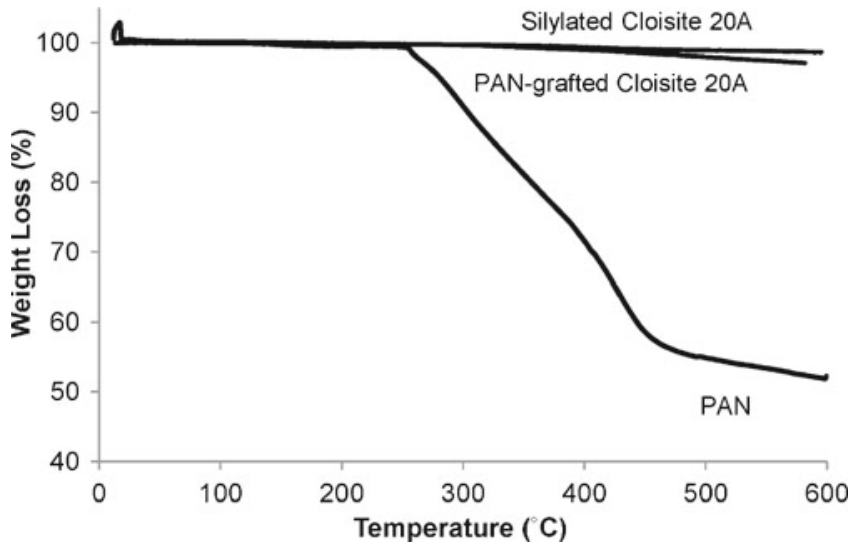

Figure 3. TGA thermograms $\left(\mathrm{N}_{2}\right.$ atmosphere, scan rate of $10^{\circ} \mathrm{C} /$ min) of PAN, silylated Cloisite 20A and PAN-grafted Cloisite 20A.

grafted onto the montmorillonite surface. A schematic representation for grafted clay particle is shown in figure 2 . Therefore, a wide range of grafted organoclay materials with desired polarities can be prepared by utilizing this approach with vinyl monomers of different polarities.

The amount of grafted polymer can be estimated by TGA measurement (Wheals 1975; Waddell et al 1981; Zhang et al 2006; Mansoori et al 2011). Figure 3 shows TGA curves of silylated Cloisite 20A, PAN-grafted Cloisite 20A and pristine PAN. After prolonged Soxhlet extraction of the PAN-grafted Cloisite 20A it was found to give a significant weight loss 


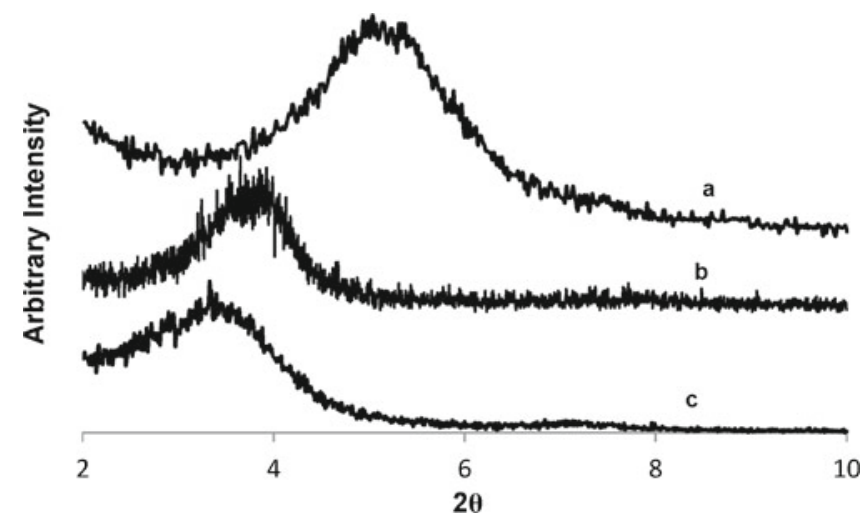

Figure 4. Wide-angle powder X-ray diffraction patterns of (a) Cloisite 20A, (b) silylated Cloisite 20A and (c) PAN-grafted Cloisite 20A.

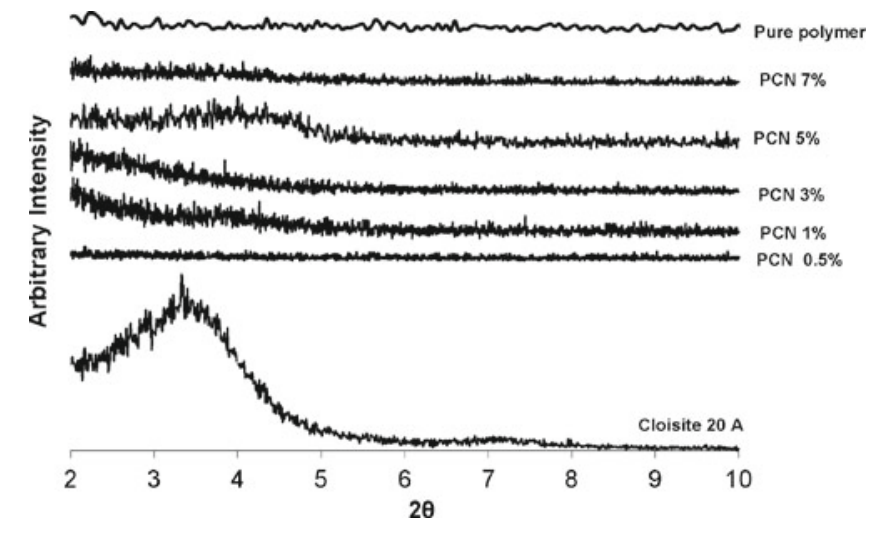

Figure 5. Wide-angle powder X-ray diffraction patterns of Cloisite 20A and PAN-clay nanocomposites.

Table 1. Diffraction peaks and basal spacing of Cloisite 20A, silylated Cloisite 20A, PAN-grafted Cloisite 20A and nanocomposites.

\begin{tabular}{lcc}
\hline & \multicolumn{2}{c}{ Diffraction peak and basal spacing } \\
\cline { 2 - 3 } Product & Typical diffraction peak $\left(^{\circ}\right)$ & Basal spacing (nm) \\
\hline Cloisite 20A & $3 \cdot 42$ & $2 \cdot 6$ \\
Silylated Cloisite 20A & $3 \cdot 70$ & $2 \cdot 4$ \\
PAN-grafted Cloisite 20A & $5 \cdot 14$ & $1 \cdot 7$ \\
${ }^{\text {aPCN 0.5\% }}$ & - & - \\
PCN 1\% & - & - \\
PCN 3\% & - & - \\
PCN 5\% & - & - \\
PCN 7\% & - & - \\
\hline
\end{tabular}

${ }^{\text {a}}$ Polymer-clay nanocomposites.

after ashing at $600^{\circ} \mathrm{C}$. This weight loss starts at $275^{\circ} \mathrm{C}$ that is higher than that of main step decomposition of pristine PAN $\left(T_{\mathrm{D}}=260^{\circ} \mathrm{C}\right)$. The difference between weight losses of silylated Cloisite 20A and PAN-grafted Cloisite 20A after ashing at $600^{\circ} \mathrm{C}(\Delta m=1.76 \%)$ can be attributed to weight of the grafted polymer. Therefore, amount of grafted polymer $(17.6 \mathrm{mg} / \mathrm{g}$ of clay) can be calculated from (1).

$$
\text { Grafted amount }(\mathrm{mg} / \mathrm{g})=\frac{\Delta m}{100} \times 1000 \text {. }
$$

Wide-angle powder X-ray diffraction patterns of Cloisite 20A, silylated Cloisite 20A and PAN grafted Cloisite 20A are shown in figures $4 \mathrm{a}-\mathrm{c}$. A strong peak is observed at $2 \theta=3.42^{\circ}$, corresponding to the (001) plane for Cloisite $20 \mathrm{~A}$, indicating that the interlayer $d$-spacing of the organoclay is $\sim 2.6 \mathrm{~nm}$. This value is comparable to the value $(2.4 \mathrm{~nm})$ reported by the supplier (Southern Clay Products, Inc.). The interlayer $d$-spacing is slightly decreased to $2.4 \mathrm{~nm}$ $\left(2 \theta=3 \cdot 70^{\circ}\right)$ after silylation that is in agreement with results reported earlier (Zhang et al 2006). This can attributed to partial exchange of ammonium groups by $\mathrm{H}+$ ions. The interlayer $d$-spacing reaches $1.7 \mathrm{~nm}\left(2 \theta=5.14^{\circ}\right)$ after grafting and complete drying. The diffraction peaks and calculated basal spacings of the products are summarized in table 1 .

The wide-angle powder X-ray diffraction patterns of Cloisite 20A and a series of PAN-clay nanocomposite materials are shown in figure 5 and summarized in table 1 . No peak is observed at a clay loading of $0.5-7 \mathrm{wt} \%$ (PCN $0.5-7 \%)$ at $2 \theta=2-10^{\circ}$, as opposed to the peak at $2 \theta=$ $3.42^{\circ}(d$-spacing $=2.6 \mathrm{~nm})$ for Cloisite 20A. This observation indicates less agglomeration and potentially exfoliated nanocomposites at a clay loading of 0.5-7 wt $\%$.

Generally, the absence of diffracting peak would indicate an exfoliated structure or full disordering. In the case of intercalated nanocomposites, polymer chains are inserted into the clay galleries; however, the clay platelets are still organized into an ordered structure despite swelling of the galleries. The absence of diffraction peaks in WXRD patterns should not be used as sole evidence for the formation of an exfoliated structure because factors such as clay dilution and peak broadening can yield false results that show that exfoliation has occurred. Other factors, such as the preferred orientation effect, can lead to false conclusions that exfoliation has not occurred. In this study, insertion of polymer chains into 

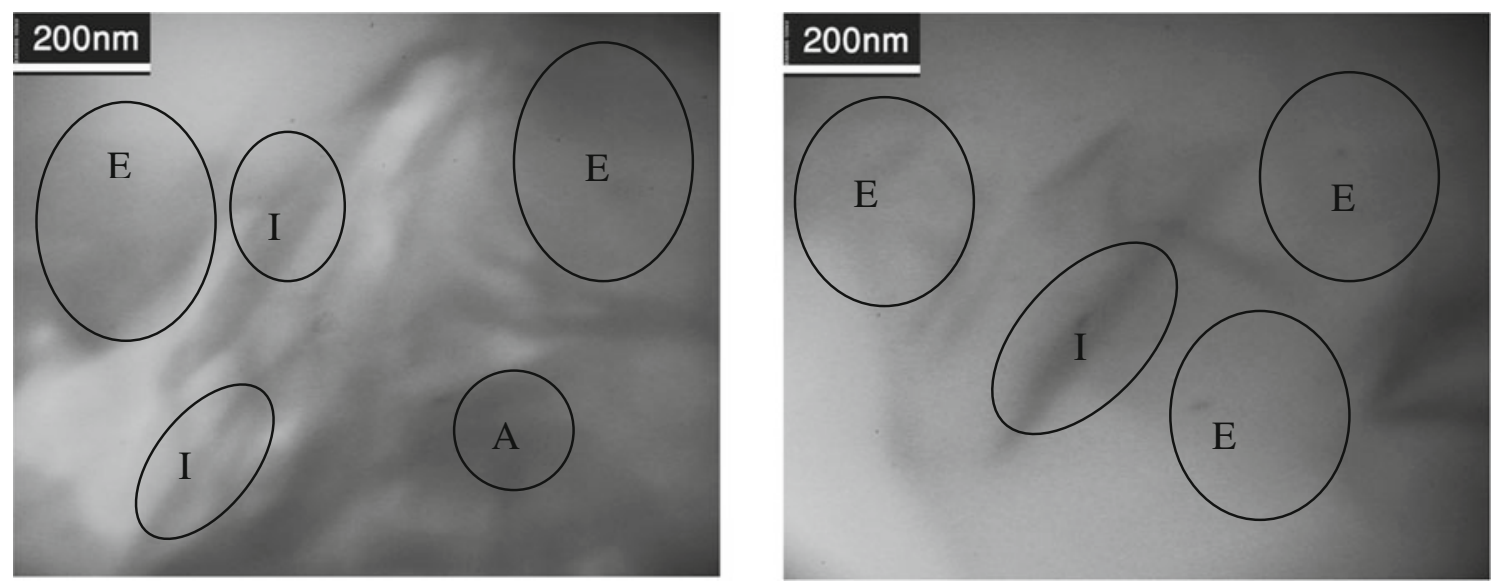

Figure 6. TEM micrographs of PCN $1 \%$ showing formation of exfoliated structures.

Table 2. Thermal and mechanical analysis (DMTA and TGA) results.

\begin{tabular}{|c|c|c|c|c|c|c|c|c|c|c|}
\hline \multirow[b]{2}{*}{ Polymer } & \multirow[b]{2}{*}{$T_{\mathrm{g}}\left({ }^{\circ} \mathrm{C}\right)^{\mathrm{a}}$} & \multirow{2}{*}{$\begin{array}{l}10 \% \text { Weight } \\
\text { loss }\left({ }^{\circ} \mathrm{C}\right)^{\mathrm{b}}\end{array}$} & \multirow[b]{2}{*}{$T_{\mathrm{D} 1}\left({ }^{\circ} \mathrm{C}\right)^{\mathrm{c}}$} & \multirow[b]{2}{*}{$T_{\mathrm{D} 2}\left({ }^{\circ} \mathrm{C}\right)^{\mathrm{d}}$} & \multirow[b]{2}{*}{ Char yield $^{\mathrm{e}}$} & \multicolumn{5}{|c|}{ Storage modulus (GPa) } \\
\hline & & & & & & $-20{ }^{\circ} \mathrm{C}$ & $0^{\circ} \mathrm{C}$ & $40^{\circ} \mathrm{C}$ & $70^{\circ} \mathrm{C}$ & $85^{\circ} \mathrm{C}$ \\
\hline Pure PAN & $87 \cdot 6$ & $301 \cdot 8$ & $259 \cdot 1$ & $353 \cdot 3$ & $51 \cdot 7$ & $7 \cdot 27$ & $7 \cdot 09$ & $6 \cdot 60$ & $5 \cdot 85$ & $5 \cdot 06$ \\
\hline PCN $0.5 \%^{f}$ & $101 \cdot 6$ & $333 \cdot 4$ & $268 \cdot 1$ & $358 \cdot 8$ & $63 \cdot 4$ & 2.79 & $2 \cdot 78$ & $2 \cdot 72$ & 2.59 & 2.47 \\
\hline PCN $1 \%$ & $94 \cdot 1$ & $286 \cdot 8$ & $269 \cdot 0$ & $361 \cdot 9$ & $47 \cdot 2$ & $2 \cdot 70$ & $2 \cdot 65$ & $2 \cdot 56$ & $2 \cdot 50$ & $2 \cdot 36$ \\
\hline PCN $3 \%$ & $90 \cdot 2$ & $291 \cdot 1$ & $269 \cdot 4$ & $363 \cdot 2$ & $53 \cdot 3$ & $5 \cdot 73$ & $5 \cdot 63$ & $5 \cdot 33$ & $4 \cdot 87$ & $4 \cdot 38$ \\
\hline PCN $5 \%$ & $89 \cdot 9$ & $292 \cdot 4$ & $272 \cdot 3$ & $364 \cdot 4$ & $52 \cdot 5$ & $4 \cdot 50$ & $4 \cdot 42$ & $4 \cdot 17$ & $3 \cdot 88$ & $3 \cdot 64$ \\
\hline $\mathrm{PCN} 7 \%$ & 89.7 & 289.8 & $275 \cdot 0$ & $365 \cdot 3$ & $53 \cdot 6$ & $6 \cdot 09$ & 5.99 & $5 \cdot 63$ & $5 \cdot 18$ & $4 \cdot 46$ \\
\hline
\end{tabular}

${ }^{\mathrm{a}}$ Obtained from DMTA measurements based on $\tan \delta$ versus temperature curves; ${ }^{\mathrm{b}}$ obtained from TGA measurements; ${ }^{\mathrm{c}}$ initiation temperature of first stage decomposition; ${ }^{\mathrm{d}}$ initiation temperature of second stage decomposition; ${ }^{\mathrm{e}}$ at $600{ }^{\circ} \mathrm{C}$; ${ }^{\mathrm{f}}$ measurement was repeated on sample prepared separately.

the clay galleries increased the clay spacing compared to the pristine Cloisite 20A. The formation of either intercalated or exfoliated nanocomposites can be confirmed by TEM. Figure 6 shows representative TEM micrographs of the PCN $1 \%$. These micrographs reveal the formation of exfoliated structure. In this regard, TEM can provide useful information and conclusive evidence concerning the morphology, structure and spatial distribution of dispersed clay platelets in the polymer matrix (Tjong and Ruan 2008). In addition, TEM photographs could allow us to establish the silicate dispersion grade. Thus, in the image of PCN $1 \%$, regions where silicate aggregates are found, indicated as " $A$ ", as well as regions where some intercalated and exfoliated platelets are found, indicated as " $I$ " and " $E$ ", respectively are observed. The clay is homogeneously distributed in the matrix and the clay aggregates are not large.

The results of thermal and mechanical analyses by TGA and DMTA are summarized in table 2. The $T_{\mathrm{g}}$ value increases from $87.6^{\circ} \mathrm{C}$ for pure PAN to $101 \cdot 6^{\circ} \mathrm{C}$ for PCN $0.5 \%$. This observation is tentatively attributed to the interaction of polymer chains with the clay galleries that prevents the segmental motions of the polymer chains (Liu and Guo 2006). However, further addition of organoclay up to $7 \mathrm{wt} \%$ leads to a decrease in $T_{\mathrm{g}}$. This decrease might be due to the aggregation of organoclay particles that reduces the interfacial interaction between organoclay and PAN matrix (Ray and Okamoto 2003). Additionally, a large amount of intercalating reagents in the organophilic clay may act as a plasticizer or as a lubricant; the glass transition temperature is lower than that with a low amount of clay (Liqiang et al 2008). DMTA curves of PAN and nanocomposites with $0.5-7 \mathrm{wt} \%$ clay loadings are shown in figure 7.

Variation of storage modulus with temperature for PAN and its nanocomposites has been shown in figure 8. A considerable decrease in storage modulus is observed for PCN $0.5 \%$ and PCN $1 \%$ with respect to virgin polymer especially below glass transition temperature. This may be due to the difference in the polarity of the polymer matrix and the surfactant used in the modification of the organoclay. PAN is a quite polar polymer while in the Cloisite 20A the clay particles are lipophilized with a quaternary alkyl ammonium salt having long alkyl chain that is non-polar. This factor destroys the crystallinity of PAN matrix especially at low clay loadings. For PCN $1-7 \%$ the storage modulus is influenced by the amount of grafted clay and increases with increasing organoclay content. 


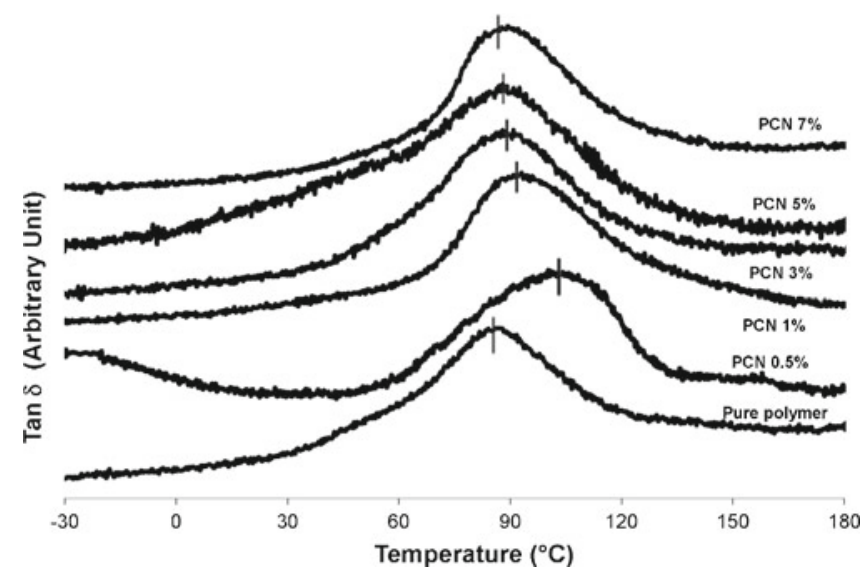

Figure 7. DMTA curves of PAN and PAN-clay nanocomposite materials (PCNs)

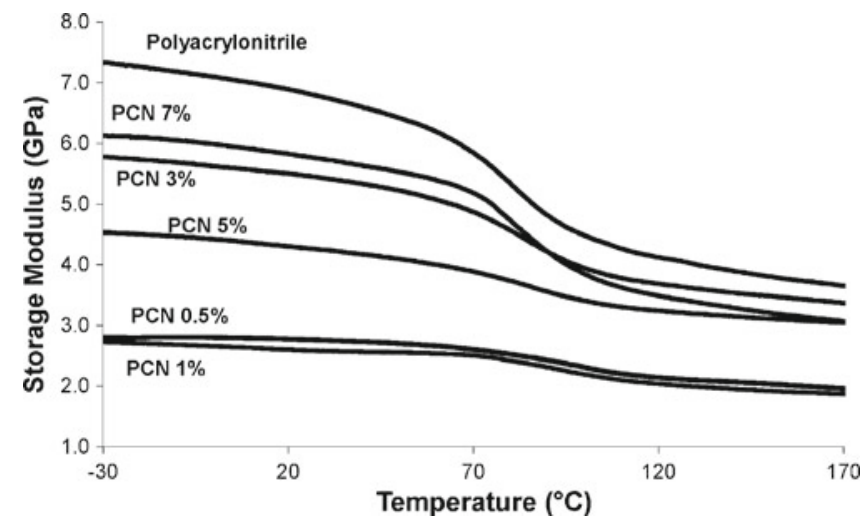

Figure 8. Temperature dependence of storage modulus of PAN and PAN-clay nanocomposite materials (PCNs).

The dynamic properties of PAN and its nanocomposites at various temperatures are summarized in table 2 . It is observed that in the PCN materials the drop in the storage moduli below glass transition temperature occurs slower than that for pure PAN. For example, storage moduli of pure PAN and PCN $0.5 \%$ change from 7.27 and $2.79 \mathrm{GPa}$ at $-20{ }^{\circ} \mathrm{C}$ to 5.85 and $2.59 \mathrm{GPa}$ at $70^{\circ} \mathrm{C}$, respectively. This can be attributed to the fact that, for pure PAN, the polymer crystallinity can be destroyed only by heating near the glass transition temperature. While, as mentioned above, in the cases of PCN materials the crystalline structure of the polar polymer matrix was partly destroyed by PAN-grafted organoclay and cannot be further influenced by heating near glass transition temperature.

TGA curves of PAN and nanocomposites with 0.5-7 wt $\%$ clay loadings are shown in figure 9. Pure PAN and its nanocomposites are observed to degrade through two steps in $\mathrm{N}_{2}$ atmosphere. In the first step, the cyclization of $\mathrm{CN}$ groups in a polyconjugated structure, happens at about $259-275^{\circ} \mathrm{C}$, immediately followed by the aromatization step with loss of hydrogen molecules and the formation of a laddered aromatic

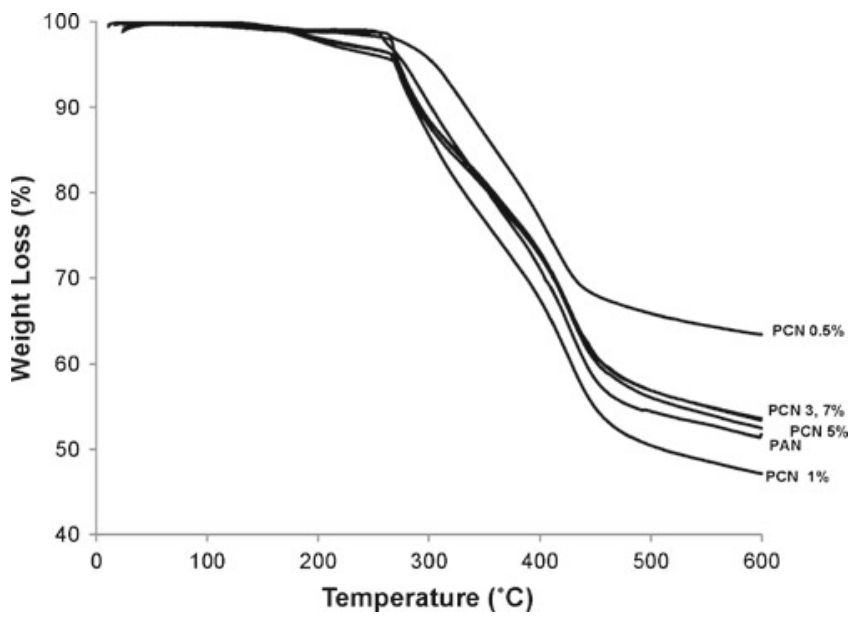

Figure 9. TGA thermograms $\left(\mathrm{N}_{2}\right.$ atmosphere, scan rate of $10^{\circ} \mathrm{C} / \mathrm{min}$ ) of PAN, PCN $1 \%$, PCN 3\%, PCN 5\% and PCN $7 \%$.

structure. In the second step, heating at temperatures above $350^{\circ} \mathrm{C}$ results in lateral condensation of laddered structures, with loss of hydrogen (Hay 1968; Grassie and Macguchan 1970; Beretta 2009). As seen from the data collected in table 2, temperature of $10 \%$ weight loss and char yield at $600^{\circ} \mathrm{C}$ are significantly increased in PCN $0.5 \%$ with respect to virgin polymer. Similar results were obtained for the sample prepared separately. This may be due to better miscibility and high interaction between the polymer and the clay for PCN $0.5 \%$. The initiation temperatures for the first and second stages $\left(T_{\mathrm{D} 1}\right.$ and $\left.T_{\mathrm{D} 2}\right)$ are also increased with increasing clay loading for PCNs $0.5-7 \%$. The improvement of thermal stability can be attributed to the barrier effect of organoclay. Cloisite 20A is a layered structure and small molecules generated during thermal decomposition process cannot permeate, and thus have to bypass Cloisite 20A layers (Santiago et al 2007).

\section{Conclusions}

PAN was chemically grafted onto Cloisite 20A after silylation of the edge silanol groups of the clay by vinyltrichlorosilane. To demonstrate successful grafting, the homopolymer formed during polymerization was separated from grafted Cloisite 20A by Soxhlet extraction. Chemical grafting of the polymer onto the Cloisite 20A surface was confirmed by FTIR spectroscopy. The interlayer $d$-spacing of the grafted organophilic clay was investigated by WXRD. Polymer-clay nanocomposites with different clay contents were prepared by free radical copolymerization of vinyl-silylated Cloisite $20 \mathrm{~A}$ and $\mathrm{AN}$ monomer in DMF. The interlayer $d$-spacing and surface changes in the prepared nanocomposite materials were studied by WXRD and TEM. Exfoliated nanocomposites were obtained for PCN 1\%. The thermal and mechanical properties of the nanocomposites were also studied by TGA and DMTA. Based on these measurements, it is observed that 
the glass transition temperature $\left(T_{\mathrm{g}}\right)$ and thermal stability are improved in PCN $0.5 \%$ with respect to pristine polymer. This observation is tentatively attributed to the better miscibility and effective interaction between polymer and exfoliated organoclay at low clay loading.

\section{Acknowledgement}

The Graduate Council of the University of Mohaghegh Ardabili, Iran, is gratefully acknowledged for financial support.

\section{References}

Agudelo N A, Perez L D and Lopez B L 2011 Appl. Surf. Sci. 257 8581

Beretta M 2009 Nanostructured mesoporous materials obtained by template synthesis and controlled shape replica, Ph.D Thesis, University of Milano, Bicocca

Chen J C, Luo W Q, Wang H D, Xiang J M, Jin H F, Chen F and Cai Z W 2010 Appl. Surf. Sci. 2562490

Chen Y S, Chen C C and Hou S S 2010 J. Appl. Polym. Sci. 115416

Choi Y S and Chung I J 2004 Polymer 453827

Choi Y S, Wang K H, Mingzhe X and Chung I J 2002 Chem. Mater. 142936

Fan X, Xia C, Fulghum T, Park M K, Locklin J and Advincula R C 2003a Langmuir 19916

Fan X, Xia C and Advincula R C 2003b Langmuir 194381

Feng M, Chen Y, Gu L, He N, Bia J, Lin Y and Zhan H 2009 Eur. Polym. J. 451058

Gintert M J, Jana S C and Miller S G 2007 Polymer 484166

Gorgani M N, Karimian K and Mohanazadeh F 1985 J. Am. Chem. Soc. 1074156

Grassie N and Macguchan R 1970 Eur. Polym. J. 61277

Gu A, Kuo S W and Chang F C 2001 J. Appl. Polym. Sci. 791902

Hay J N 1968 J. Polym. Sci. Part A. Polym. Chem. 62127

Herrera N N, Letoffe J M, Putaux J L, David L and Lami E B 2004 Langmuir 201564

Huang C C, Jang G W, Chang K C, Hung W I and Yeh J M 2008 Polym. Int. 57605

Huang J C, Zhu Z K, Yin J, Qian X F and Sun Y Y 2001 Polymer 42873

Jia Q X, Wu Y P, Wang Y Q, Lu M and Zhang L Q 2008 Compos. Sci. Technol. 681050

Jin H S and Chang J H 2008 J. Appl. Polym. Sci. 107109

Karimi P, Rafizadeh M and Taromi F A 2011 J. Hazard. Mater. 186 182
Kim J H, Ganapathy H S, Hong S S, Gul Y S and Lim K T 2008 J. Supercrit. Fluids $\mathbf{4 7} 103$

Liqiang C, Naresh H T and Seong I W 2008 J. Appl. Polym. Sci. 110784

Liu P and Guo J 2006 Colloids Surf. A498 282

Mansoori Y, Atghia S V, Shah Sanaei S, Zamanloo M R and Imanzadeh Gh 2010a Macromol. Res. 181174

Mansoori Y, Atghia S V, Zamanloo M R, Imanzadeh Gh and Sirousazar M 2010b Eur. Polym. J. 461844

Mansoori Y, Akhtarparast A, Zamanloo M R, Imanzadeh Gh and Masooleh T M 2011 Polym. Compos. 321225

Mittal V 2007 J. Colloid. Interf. Sci. 314141

Nataraj S K, Him B H, Yun J H and Lee D H 2009 Mater. Sci. Eng. B162 75

Njuguna J, Pielichowski K and Desai S 2008 Polym. Adv. Technol. 19947

Phang I Y et al 2005 Polym. Int. 54456

Qiao Z, Xie Y, Zhu Y and Qian Y 1999 J. Mater. Chem. 91001

Ray S S and Okamoto M 2003 Prog. Polym. Sci. 281539

Rubal M, Wilkins C W, Cassidy P E, Lansford C and Yamada Y 2008 Polym. Adv. Technol. 191033

Santiago F, Mucientes A E, Osorio M and Rivera C 2007 Eur. Polym. J. 431

Stefanescu E A, Stefanescu C, Daly W H, Schmidt G and Negulescu II 2008 Polymer 493785

Sun D, Li Y, Zhang B and Pan X 2010 Compos. Sci. Technol. 70 981

Tjong S C and Ruan Y H 2008 J. Appl. Polym. Sci. 110864

Waddell T G, Leyden D E and Debello M T 1981 J. Am. Chem. Soc. 1035303

Wang C, Xue T, Dong B, Wang Z and Li H 2008 Wear 2651923

Wang T, Wang M, Zhang Z, Ge X and Fang Y 2007 Mater. Lett. 61 3723

Wang Y et al 2005 Mater. Lett. 593046

Wheals B B 1975 J. Chromatogr. 107402

Yang Y W, Chen Y T, Chen H C, Lin W T and Tsai C H 2009 Polymer $\mathbf{5 0} 2856$

Yu T, Lin J, Xu J, Chen T, Lin S and Tain X 2007 Compos. Sci. Technol. 673219

Yudin V E, Otaigbe J U, Gladchenko S, Olson B G, Nazarenko S, Korytkova E N and Gusarov V V 2007 Polymer 481306

Zhang D, Karki A B, Rutman D, Yang D P, Wang A, Cocke D, Ho T H and Guo Z 2009 Polymer 504189

Zhang D, Chung R, Karki A B, Li F, Young D P and Guo Z 2010 J. Phys. Chem. C114 212

Zhang J, Gupta R K and Wilkie C A 2006 Polymer 474537

Zhao F, Wan Y, Bao X and Kandasubramanian B 2009 J. Colloid. Interf. Sci. 333164

Zhao X Y and Wang M Z 2006 J. Appl. Polym. Sci. 1003116 